\title{
Developmental exposure window influences silver toxicity but does not affect the susceptibility to subsequent exposures in zebrafish embryos
}

\author{
Paige C. Robinson ${ }^{1,2}$ (D) Hannah R. Littler ${ }^{1,2}$ (D) $\cdot$ Anke Lange $^{1}$ (D) $\cdot$ Eduarda M. Santos $^{1,3}$ (D)
}

Accepted: 7 October 2020 / Published online: 21 October 2020

(c) The Author(s) 2020

\begin{abstract}
Silver is a non-essential, toxic metal widespread in freshwaters and capable of causing adverse effects to wildlife. Its toxic effects have been studied in detail but less is known about how sensitivity varies during development and whether preexposures affect tolerance upon re-exposure. We address these knowledge gaps using the zebrafish embryo (Danio rerio) model to investigate whether exposures encompassing stages of development prior to mid-blastula transition, when chorion hardening and epigenetic reprogramming occur, result in greater toxicity compared to those initiated after this period. We conducted exposures to silver initiated at $0.5 \mathrm{~h}$ post fertilisation (hpf) and $4 \mathrm{hpf}$ to determine if toxicity differed. In parallel, we exposed embryos to the methylation inhibitor 5-azacytidine as a positive control. Toxicity increased when exposures started from $0.5 \mathrm{hpf}$ compared to $4 \mathrm{hpf}$ and LC50 were significantly lower by 1.2 and 7.6 times for silver and 5-azacyitidine, respectively. We then investigated whether pre-exposure to silver during early development (from $0.5 \mathrm{or} 4 \mathrm{hpf}$ ) affected the outcome of subsequent exposures during the larvae stage, and found no alterations in toxicity compared to naïve larvae. Together, these data demonstrate that during early development zebrafish embryos are more sensitive to silver when experiments are initiated at the one-cell stage, but that pre-exposures do not influence the outcome of subsequent exposures, suggesting that no long-lasting memory capable of influencing future susceptibility was maintained under our experimental conditions. The finding that toxicity is greater for exposures initiated at the one-cell stage has implications for designing testing systems to assess chemical toxicity.
\end{abstract}

Keywords Pulsed exposure $\cdot$ Repeated exposure $\cdot$ Danio rerio $\cdot$ Teleost $\cdot$ Sensitivity

\section{Introduction}

Silver is a non-essential, toxic metal capable of causing damage to biodiversity in aquatic systems worldwide. Growing applications of silver nanoparticles in industrial processes (Thamilselvi and Radha 2017) and the resulting increase in contamination of the environment have made silver an increasingly important pollutant to study. The bioavailability and toxicity of silver vary greatly depending on environmental conditions (Paquin and Di Toro 2008), life stage (Groh et al. 2015), and mode of uptake (Hogstrand and Wood 1998). However, the precise mechanisms underpinning variation in toxicity remain understudied. Understanding the determinants of susceptibility and the impact that multiple exposures have on individuals and populations is important for the protection of ecosystems.

The predominant sources of silver pollution have varied over the last few decades. Initial concerns related to 
the discharge of silver by the photographic industry in the twentieth century, with concentrations reaching up to $1 \mathrm{~g} /$ $\mathrm{kg}$ in soils and $38 \mu \mathrm{g} / \mathrm{L}$ in aquatic environments near mining sites (Purcell and Peters 1998). Legislation to limit pollution in Europe, Australia and New Zealand defined a safe limit for ionic silver as $0.05 \mu \mathrm{g} / \mathrm{L}$, while limits are $0.1 \mu \mathrm{g} / \mathrm{L}$ and $3.2 \mu \mathrm{g} / \mathrm{L}$ for Canada and the USA, respectively (Kwak et al. 2016). These regulations led to concentrations being substantially reduced in the environment (Juncos et al. 2017). Recently, the broad utility of silver nanoparticles as a catalytic agent in green synthesis (Razack et al. 2016) and as an antibacterial agent in the textile industry (Dubas et al. 2006), wound healing (Kumar et al. 2018) and water treatment (Chen et al. 2017; Ngoc Dung et al. 2019) have led to an increase in the concentrations of silver in aquatic systems. As the most commercialised nanomaterial worldwide (Valerio-García et al. 2017), around 500 tonnes of silver nanoparticles are produced each year (Kwak et al. 2016), and once they enter aquatic environments, silver ions on the nanoparticle surface can dissolve over time, increasing the toxic effect on organisms (Garcia-Reyero et al. 2015). Recorded silver ion levels recently ranged from 40 to $320 \mathrm{ng} / \mathrm{L}$ in the river Rhine, Germany (McGillicuddy et al. 2017), and concentrations are expected to continue to increase. Once silver enters the environment, it can occur in a variety of molecular species depending on other environmental variables, including $\mathrm{pH}$, salinity, and presence of organic matter in the water, resulting in varying toxicity. Biotic Ligand Models (BLMs) incorporate this information and are used to estimate toxicity in a given environment (Paquin and Di Toro 2008).

Freshwater fish are particularly vulnerable to silver as it is transported into gill ionocytes via sodium ion channels. Once inside the cell, it binds at $\mathrm{Mg}^{2+}$ binding sites on the cytoplasmic side of the basolateral $\mathrm{Na}^{+}-\mathrm{K}^{+}$ATPase pump, preventing ATP hydrolysis and inhibiting sodium and chloride transport between the gill ionocyte and the blood plasma (Bury et al. 1999). As gills are the main site of osmoregulation, the loss of ions from blood plasma can cause circulatory collapse of fluid volume regulation due to increased blood viscosity and increased pressure on the cardiovascular system. Ion transport interruption can also cause an increase in intracellular acidity which can initiate a branchial inflammatory response, increasing mucus production and interrupting gas transfer. This respiratory inhibition is less severe than the osmoregulatory effect, but can be lethal if silver concentration causes damage to the gill epithelium and blood oxygen tension drops (Hogstrand and Wood 1998). Once silver crosses the gill epithelium and enters the blood stream, it is transported by macroglobulins, such as ceruloplasmin, hijacking the transport mechanism for essential metals (Hanson et al. 2001). Silver is then deposited in hepatic and renal cells among others, where metallothionein and other metal chaperones bind to inactivate and transport silver for excretion (Lansdown 2006). Hepatic excretion through exocytosis into the bile is the main pathway for silver removal with renal excretion through blood filtration also contributing to removal of silver ions from the blood stream (Kleiven et al. 2018).

During embryonic development in fish, silver exposure and uptake differ from that observed in adults due to the absence of functional gills and to chorion permeability changes during the first few hours post fertilisation (hpf). Silver has been observed throughout embryo tissues when concentrations exceed $30 \mu \mathrm{g} / \mathrm{L}$ (Böhme et al. 2017). Before the development of functioning gills, ionocytes across the epithelial surface are the main site of ion regulation (Fu et al., 2010) and gas exchange (Wells and Pinder 1996). Embryos are likely to be more sensitive than adult fish to silver exposure due to their incomplete development and suboptimal protective mechanisms (Groh et al. 2015). For exposures initiated during the first two hours of zebrafish development, silver concentrations within embryo tissues were observed to be up to 20 times higher compared to exposures later in development (Böhme et al. 2015). This has been linked to the permeability of the chorion during this early developmental stage as it swells adapting to the change in osmotic pressure post fertilisation (Peterson and Martin-Robichaud 1982). Once the chorion has hardened by $4 \mathrm{hpf}$, it has been shown to act as a protective barrier against silver uptake in zebrafish embryos (Guadagnolo et al. 2001). Silver ions have also been shown to accumulate within oocytes in exposed adult females, further increasing the exposure concentration, and thus sensitivity during early life stages, although most of the recorded silver accumulation was located in chorion structures (Böhme et al. 2017).

Similarly to other toxic metals, silver can cause oxidative damage to DNA, lipids and proteins due to acting as a catalyst to increase the production of reactive oxygen species (Vandegehuchte and Janssen 2011). Silver also alters the functioning of multiple molecular pathways including oxidative phosphorylation (van Aerle et al. 2013), immune response (Garcia-Reyero et al. 2015), cell cycling (Kang et al. 2016), and calcium signalling (Xu et al. 2018). Metallothionein upregulation was observed in 72 and $96 \mathrm{hpf}$ zebrafish embryos after $24 \mathrm{~h}$ of silver exposure prior to sampling (Boyle and Goss 2018), and genes related to olfactory bulbs and lateral line neuromasts, as well as skin ionocytes, were also affected when exposures were initiated at $1 \mathrm{hpf}$ (Osborne et al. 2016). Silver has also been shown to cause epigenetic modifications in fish, which can alter gene transcription long after the exposure has ended (Xu et al. 2018).

In freshwater ecosystems, pollutant concentrations often fluctuate rapidly over time, resulting in intermittent exposures (Handy 1994), which can alter organism response due to toxicodynamic recovery (Ashauer et al. 2017). Despite this, the impacts of variable exposure conditions on 
individuals and populations have rarely been studied, and this is a priority for study, especially for exposures occurring at vulnerable life stages (Plautz and Salice 2013). Experiments conducting repeated exposures for various chemicals have resulted in either increased or decreased sensitivity when organisms were re-exposed compared to the naive response. When exposed to $17 \alpha$-ethinyloestradiol during the first $48 \mathrm{~h}$ of development, zebrafish show increased sensitivity to subsequent oestrogen exposures later in development (Green et al. 2018), and similar results were observed following intermittent exposures to $17 \alpha$-ethinyloestradiol in roach (Lange et al. 2009). Higher concentrations of fenvalerate were recorded in intermittently exposed trout as opposed to those continuously exposed (Curtis et al. 1985), and pulsed exposures to copper during early development were also shown to be more toxic than a continuous exposure at the same concentration (Boyle et al. 2020). However, if adult fish were given time to acclimate to near lethal copper concentrations, an increase in tolerance was observed (Anadu et al. 1989), usually attributed to increased metallothionein expression (Bradley et al. 1985). Genetic variation in populations may partially contribute towards observed tolerance to metal exposure as observed in earthworms (Kille et al. 2013); however, epigenetic DNA methylation alterations in response to altered conditions have also been observed to increase tolerance in stickleback after marine to freshwater movement (Artemov et al. 2017), and human lympoblast cells after acclimation to cadmium (Ye et al. 2014). More work is needed to understand the impact of repeated exposures on organisms at the physiological and molecular level.

The timing of initial exposure during embryo development is also important to consider as it has been shown to be crucial in the toxicity of various chemicals, including silver, due to the dynamic nature of the processes occurring during early developmental stages (Böhme et al. 2015; Groh et al. 2015). During the first four hours of zebrafish development, rapid cell proliferation and epigenetic reprogramming occur to allow for cell specification, uniform chromatin architecture and the removal of deleterious markers (Jiang et al. 2013; Potok et al. 2013; Skvortsova et al. 2018). At this time, it is hypothesised that the epigenome is more susceptible to alterations due to stressor exposure, potentially increasing the toxicity of stressors capable of disrupting it (Gellert and Heinrichsdorff 2001). This is supported by data for the methylation inhibitor 5-azacytidine which has been shown to alter zebrafish methylation and cause developmental abnormalities when exposures occur during the reprogramming period at $2-3 \mathrm{hpf}$; however, toxicity is significantly reduced when exposures occur after reprogramming is complete (> 6 hpf; Martin et al. 1999; Kamstra et al. 2017). Zygotic genome activation (ZGA) also occurs during early development at the mid-blastula transition (Pálfy et al. 2017), after which embryos are able to more readily modify transcript abundance and protein synthesis in response to chemical exposure, providing another hypothesis to explain potential changes in sensitivity to chemical exposure during early development (reviewed in Schulz and Harrison 2019). The impact of exposures during these potential periods of sensitivity, and in particular, the effects of these exposures on the susceptibility of embryos to subsequent exposures remains poorly understood.

Here, we hypothesise that the developmental period encompassing epigenetic reprogramming will be particularly sensitive to silver exposures and most likely lead to long-lasting effects and changes in susceptibility upon reexposure due to alterations in the epigenome. To examine these hypotheses, we conducted exposures to silver $\left(\mathrm{Ag}^{+}\right)$, using the zebrafish embryo model, initiated at two periods during early development (prior to, and after, epigenetic reprogramming, chorion hardening and ZGA) to determine if the timing of initiation of exposure caused measurable changes in silver toxicity. The methylation inhibitor 5-azacytidine was used as a positive control in parallel due to its known methylation inhibitor effects during zebrafish development (Christman 2002). Further, we conducted exposures later in development with naïve and pre-exposed embryos to determine if pre-exposures during the critical windows of sensitivity defined above influenced susceptibility to future exposures.

\section{Materials and methods}

\section{Chemicals}

All chemicals were purchased from Sigma-Aldrich, Gillingham UK, unless otherwise stated, and working stock solutions were made in ultrapure water and used within two weeks.

\section{Zebrafish husbandry and embryo collection}

Adult WIK zebrafish stock populations used for embryo collection originated from a breeding population maintained at the University of Exeter and were kept under the conditions described in Paull et al. (2008). Adults were kept in $8 \mathrm{~L}$ tanks supplied with flow through standardised synthetic freshwater (according to OECD guidelines; ISO$7346 / 3$ guideline), aerated and heated to $28^{\circ} \mathrm{C}$. Fish were kept in a 12:12 light:dark cycle with gradual dawn and dusk transitions of $30 \mathrm{~min}$, and fed live Artemia once daily and GEMMA Micro pellet food, Skretting USA, twice daily.

For embryo collection, adults were randomly allocated to 20 2:1 female:male spawning chambers (3 fish per chamber) overnight with a divider separating males and females. At dawn, the divider was removed and fish 
were allowed to spawn for 10 min before embryo collection and, because of welfare considerations, fish were kept in spawning chambers for a minimum period of time. Embryos were pooled to avoid any potential bias and 50 embryos were then randomly allocated into each exposure dish containing $50 \mathrm{ml}$ of water at the appropriate exposure conditions prior to $30 \mathrm{~min}$ post fertilisation $(0.5 \mathrm{hpf})$. For exposures starting at $4 \mathrm{hpf}$, embryos were allocated to $50 \mathrm{ml}$ of control water, with chemicals added at $4 \mathrm{hpf}$.

\section{Impact of timing of initial exposure to silver or 5-azacytidine on toxicity for zebrafish embryos}

To test whether the sensitivity of embryos to silver exposure differed with the developmental stage at which exposures were initiated, we performed $48 \mathrm{~h}$ dose-response curves initiated at $0.5 \mathrm{hpf}$ or $4 \mathrm{hpf}$ (including or excluding the period of epigenetic reprogramming and the period of chorion hardening). All chemical exposures for both doseresponse curves were performed in triplicate with appropriate concentrations of each chemical added in $50 \mathrm{ml}$ aerated ISO water (according to the ISO-7346/3 guideline, ISO water diluted 1:5) with the temperature maintained at $28{ }^{\circ} \mathrm{C}$. Data were collected from three independent experiments, with each experiment using a single pool of embryos to generate full dose-response curves initiated at 0.5 and $5 \mathrm{hpf}$ (ensuring reduced technical variability between individual dishes within the same experiment and that the three experiments were independent biological replicates). The range of concentrations tested was chosen to cover a full mortality curve, based on preliminary experiments (data not shown). For $0.5-48.5 \mathrm{hpf}$ doseresponse curves, embryos were exposed to nine concentrations of silver, added in the form of silver nitrate, ranging from 0 to $60 \mu \mathrm{g} / \mathrm{L} \mathrm{Ag}^{+}$, or 5-azacytidine as a positive control, ranging from 0 to $35 \mathrm{mg} / \mathrm{L}$. Unfertilised embryos were identified by observation under a light microscope (Nikon, Japan) and removed at $3 \mathrm{hpf}$, and the number of embryos was adjusted to 20 per dish. At this time point, the stage of development was confirmed to be consistent for all embryos.

For 4-52 hpf dose-response curves, pools of 20 fertilised embryos were exposed from $4 \mathrm{hpf}$ to 9 concentrations of silver added in the form of silver nitrate, ranging from 0 to $80 \mu \mathrm{g} / \mathrm{L} \mathrm{Ag}^{+}$, or 5-azacytidine, ranging from 0 to $185 \mathrm{mg} / \mathrm{L}$, for $48 \mathrm{~h}$. Mortality and developmental endpoints were recorded after 24 and $48 \mathrm{~h}$ of exposure. The exposure water containing the appropriate concentration of silver or 5-azacytidine was replaced $24 \mathrm{~h}$ after exposure initiation and any dead embryos were recorded and removed. Unexposed embryos were maintained and assessed in parallel under the same conditions for each exposure period as a negative control. A schematic description of methods is given in Fig. 1a.

\section{Influence of pre-exposure to silver during early development on the susceptibility of larvae upon re-exposure}

To determine if pre-exposure to silver caused altered tolerance upon re-exposure, initial exposures were performed as described previously for dose-response curves, with a concentration of $30 \mu \mathrm{g} / \mathrm{L} \mathrm{Ag}^{+}$(defined as approximately the LC20 for the most sensitive period of exposure (0.5-48.5 hpf) and sufficiently high to induce adverse effects on exposed embryos). Exposures were initiated at 0.5 or $4 \mathrm{hpf}$ for $24 \mathrm{~h}$, before rinsing embryos and maintaining them in control conditions for a depuration period until $72 \mathrm{hpf}$. At this point, larvae from control, 0.5-24.5 and 4-28 hpf exposure groups were exposed to $30 \mu \mathrm{g} / \mathrm{L} \mathrm{Ag}^{+}$for $24 \mathrm{~h}$. This concentration was chosen as it caused over 50\% mortality in naïve larvae after a $24 \mathrm{~h}$ exposure initiated at $72 \mathrm{hpf}$, so any alteration in tolerance due to a pre-exposure before or after the epigenetic reprogramming period could be determined. Mortality and developmental endpoints were recorded at 48.5 and $52 \mathrm{hpf}$, and again at 72 and $96 \mathrm{hpf}$, and dead embryos were removed from dishes upon examination. Embryos from the three initial exposure conditions were maintained in parallel without undergoing a re-exposure as a negative control. For each treatment group, 6 dishes containing 20 embryos were included $(n=6$ biological replicates per treatment). A schematic description of these methods is given in Fig. 1b.

\section{Transcript profiling}

Real-time quantitative PCR (RT-QPCR) was used to quantify the transcription of target genes in zebrafish embryo pools after a $48 \mathrm{~h}$ exposure to silver and to 5-azacytidine. To do this, six replicate embryo pools $(n=20)$ were exposed to LC10 concentrations of silver (added in the form of silver nitrate, $\left.25 \mu \mathrm{g} / \mathrm{L} \mathrm{Ag}^{+}\right)$or 5 -azacytidine $(7.85 \mathrm{mg} / \mathrm{L})$ for $48 \mathrm{~h}$, initiated at 0.5 or $4 \mathrm{hpf}$. These concentrations were chosen to allow for investigation of potential mechanisms of action of the chemicals of interest rather than identifying biomarkers of overt toxicity. Embryo pools were then flashfrozen in liquid nitrogen and stored at $-80^{\circ} \mathrm{C}$. A schematic description of these methods is given in Fig. 1c. The following transcripts were selected for analysis: catalase (cat), a biomarker for oxidative stress (Yeo and Kang 2008); metallothionein $2(m+2)$ a biomarker of metal exposure (Kägi and Schäffer 1988); and DNA (cytosine-5-)-methyltransferase 1 (dnmtl) and DNA (cytosine-5-)-methyltransferase 3bb.2 (dnmt3bb.2), which encode for enzymes responsible for cytosine methylation maintenance and de novo methylation 


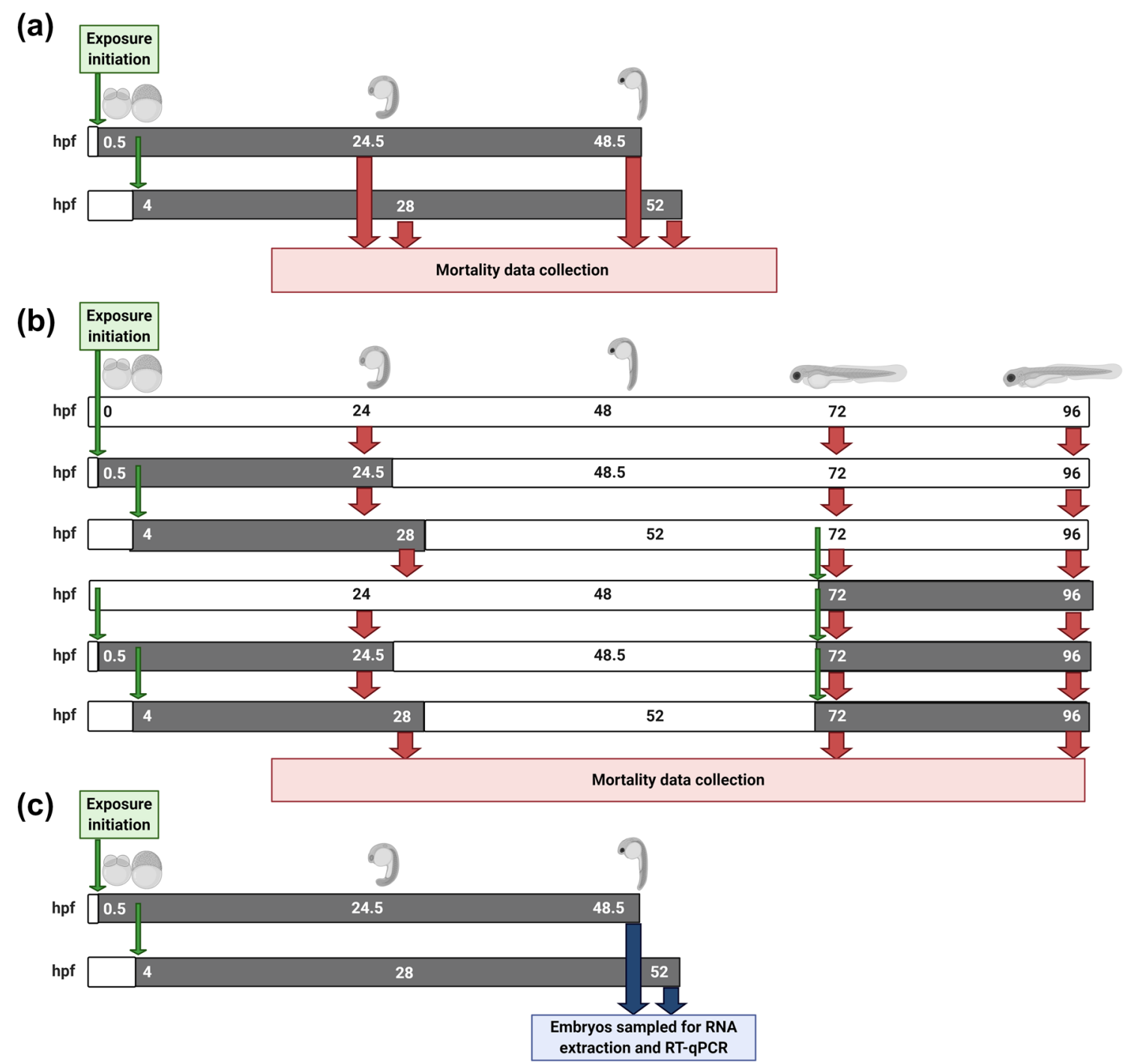

Fig. 1 Schematic of the experimental design for the experiments included in this study. a Dose-response curves for silver and 5-azacytidine when exposures were initiated at 0.5 or $4 \mathrm{hpf}$. b Repeated exposure experiments for silver to investigate if pre-exposures initiated at 0.5 and $4 \mathrm{hpf}$ influence the susceptibility of zebrafish embryos upon re-exposure. c Embryo exposure experiments to investigate the effects of exposure to silver and 5-azacytidine on transcription of target genes. Exposure periods are shown in grey bars, with clean water

(Campos et al. 2012), respectively. Primers for each target gene were designed with Beacon Designer 3.0 software (Premier Biosoft International, Paulo Alto, CA) using zebrafish NCBI Ensembl sequences, and purchased from Eurofins Genomics, Ebersberg Germany (Table 1). Primer specificity throughout the range of detection was confirmed by the observation of single amplification products of the expected size and melt temperature $\left(T_{\mathrm{m}}\right)$, and optimised by performing a standard curve for each primer pair as previously described (Laing et al. 2016). Over the detection range, the linear correlation $\left(R^{2}\right)$ between the mean $\mathrm{Ct}$ and the logarithm of the periods shown in white bars. Exposure medium was replaced every $24 \mathrm{~h}$ for every embryo pool, with the first replacement delayed until $24 \mathrm{~h}$ after exposure initiation. Green arrows represent the points of initiation of exposures, red arrows represent the points at which mortality was assessed and blue arrows represent the points where embryo samples were collected for RNA extraction. Schematics were created with BioRender.com

cDNA dilution was $>0.86$ in each case, and efficiencies were between 97.5 and 120.5. The primer sequences, PCR product sizes, annealing temperatures and PCR efficiencies for each primer pair are shown in Table 1.

RNA was extracted from six embryo pools of $n=20$ from each treatment group using the AllPrep DNA/RNA mini kit (Qiagen, Hilden, Germany), according to the manufacturer's instructions. RNA concentration and purity were assessed with a NanoDrop ND-1000 Spectrophotometer (NanoDrop Technologies, Wilmington, USA). cDNA was synthesised according to manufacturer's instructions from $1 \mu \mathrm{g}$ of total 
Table 1 Target genes, Ensembl gene IDs, gene symbols, primer sequences, amplicon product sizes, annealing temperatures $\left(T_{\mathrm{a}}\right)$, and PCR efficiencies for the qPCR assays used in this study

\begin{tabular}{|c|c|c|c|c|c|c|c|}
\hline Gene name & Ensembl gene ID & Gene symbol & $\begin{array}{l}\text { Forward primer } \\
\left(5^{\prime}-3^{\prime}\right)\end{array}$ & $\begin{array}{l}\text { Reverse primer } \\
\left(5^{\prime}-3^{\prime}\right)\end{array}$ & $\begin{array}{l}\text { Product } \\
\text { size (bp) }\end{array}$ & $T_{\mathrm{a}}\left({ }^{\circ} \mathrm{C}\right)$ & $\begin{array}{l}\text { PCR effi- } \\
\text { ciency }(\%)\end{array}$ \\
\hline ribosomal protein $L 8$ & $\begin{array}{l}\text { ENS- } \\
\text { DARG00000014867 }\end{array}$ & rpl8 & $\begin{array}{l}\text { CCGAGACCAAGA } \\
\text { AATCCAGAG }\end{array}$ & $\begin{array}{l}\text { CCAGCAACAACA } \\
\text { CCAACAAC }\end{array}$ & 91 & 57.0 & 103.8 \\
\hline catalase & $\begin{array}{l}\text { ENS- } \\
\text { DARG00000104702 }\end{array}$ & cat & $\begin{array}{l}\text { AGTTCCCTCTGA } \\
\text { TTCCTGTG }\end{array}$ & $\begin{array}{l}\text { ATGGCGATGTGT } \\
\text { GTCTGG }\end{array}$ & 173 & 61.0 & 116.3 \\
\hline metallothionein 2 & $\begin{array}{l}\text { ENS- } \\
\text { DARG00000041623 }\end{array}$ & $m+2$ & $\begin{array}{l}\text { AATGTGAATCTG } \\
\text { TTTGTCTACTCC }\end{array}$ & $\begin{array}{l}\text { GCATCGTTTTCC } \\
\text { CTCTTTAGC }\end{array}$ & 164 & 61.5 & 97.5 \\
\hline $\begin{array}{l}\text { DNA (cytosine-5)- } \\
\text { methyltransferase } 1\end{array}$ & $\begin{array}{l}\text { ENS- } \\
\text { DARG00000030756 }\end{array}$ & dnmtl & $\begin{array}{l}\text { CGCTGTCGTGTT } \\
\text { GAGTATGC }\end{array}$ & $\begin{array}{l}\text { TCCCTTGCCCTT } \\
\text { TCCTTTCC }\end{array}$ & 180 & 58.0 & 120.5 \\
\hline $\begin{array}{l}\text { DNA (cytosine-5)- } \\
\text { methyltransferase } \\
3 b b .2\end{array}$ & $\begin{array}{l}\text { ENS- } \\
\text { DARG00000057830 }\end{array}$ & $d n m t 3 b b .2$ & $\begin{array}{l}\text { TGATGCCGTGAA } \\
\text { AGTGAGTC }\end{array}$ & $\begin{array}{l}\text { TTGCCGTGTAGT } \\
\text { GATAGTGC }\end{array}$ & 172 & 58.5 & 109.5 \\
\hline
\end{tabular}

RNA treated with RQ1 DNase (Promega, Southampton, UK) using random hexamers (Eurofins Genomics) and M-MLV reverse transcriptase (Promega). cDNA was diluted 1:4 and RT-QPCR was performed in duplicate in an iCycler iQ Realtime Detection System (Bio-Rad Laboratories, Hercules, CA) using SYBR Green chemistry as described previously (Laing et al. 2016). A template-minus negative control was run in duplicate on each plate to verify the absence of DNA contamination. Efficiency-corrected relative expression levels were determined by normalising to a control gene, ribosomal protein 18 ( $r p l 8$ ), which was previously shown to have consistent expression in zebrafish embryos, including during metal exposures (van Aerle et al. 2013; Fitzgerald et al. 2016), and was found to be stable across all treatment groups (analysis of variance for cycle treshold $(\mathrm{Ct})$ values showed no differences between groups; $p=0.394$ ).

\section{Data analysis}

Mortality curves for silver and 5-azacytidine were generated in R (https://www.r-project.org/) using the drc package to run a dose-response model (drm) (Christian Ritz and Jens C. Streibig, drc R cran). To test significant differences between mortality curve models at $0.5 \mathrm{hpf}$ and $4 \mathrm{hpf}$ for each chemical and whether an interaction occurred, two-way ANOVAs were run in R. The dose-response models were used to calculate the lethal concentrations (LC) responsible for $10,20,50$ and $90 \%$ mortality after $48 \mathrm{~h}$ of exposure. These concentrations were used to inform the choice of exposure concentrations for subsequent experiments.

For re-exposure studies, barplots of average percentage mortality within each embryo pool were plotted in $\mathrm{R}( \pm \mathrm{SE})$ using ggplot2, and a Kruskal-Wallis rank-sum test was performed in $\mathrm{R}$, given that the data did not meet the assumptions of normality and equal variance required for parametric tests. When significant differences were identified, pairwise comparisons using Wilcoxon rank-sum test were performed to identify significant differences between treatment groups.

All gene transcription data were first scrutinised using the Chauvenet's criterion to detect outliers and these biological replicates (a maximum of one per treatment group) were subsequently removed before analysis (Chauvenet 1863). For each gene, data were tested for normality (Shapiro-Wilk test) and heterogeneity (Levene test) before implementing statistics. If data were found not to fit with these assumptions for parametric tests, these were then log-transformed. Transformed data were again tested for normality and equal variance and if at either stage data were normally distributed, an ANOVA and Tukey's post hoc test were performed to identify all pairwise differences between treatment groups. If even after log-transforming the data, these were not normally distributed, a non-parametric Kruskal-Wallis test was performed on the non-log-transformed data followed by Wilcoxon rank-sum post hoc test to identify differences between exposed embryos and controls. A separate model for each gene was used to test effects on gene transcription as a result of exposure to silver or 5-azacytidine. All data were considered statistically significant when $p<0.05$.

\section{Results}

\section{Impact of timing of initial exposure to silver or 5-azacytidine on toxicity for zebrafish embryos}

The developmental stage at which exposures were initiated caused significant differences in silver toxicity after 24 and $48 \mathrm{~h}$ of exposure (Fig. $2 \mathrm{a}$ and b; Table 2). Greater toxicity was observed for exposures initiated at 1-cell stage (0.5 hpf, prior to the period of epigenetic reprogramming, chorion hardening and ZGA), compared to when exposures were initiated at sphere stage ( $4 \mathrm{hpf}$, after the main period of epigenetic reprogramming, chorion hardening and the 
(a)

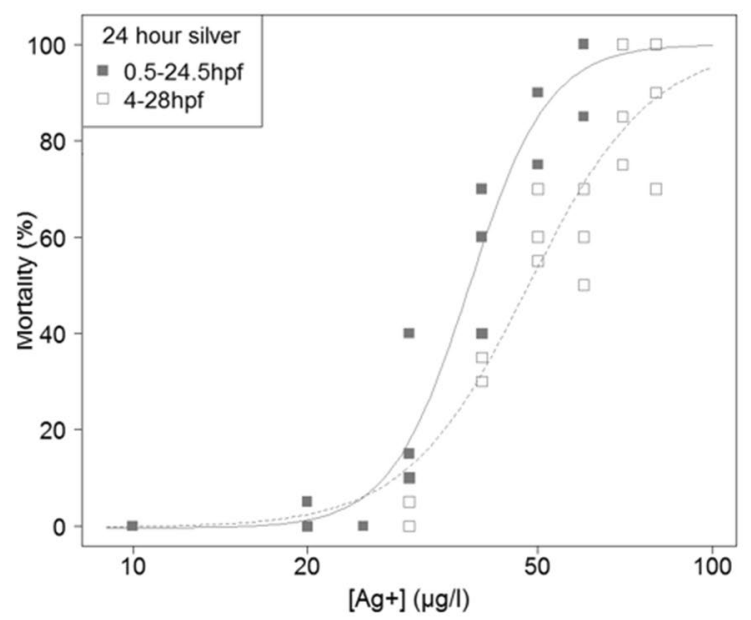

(c)

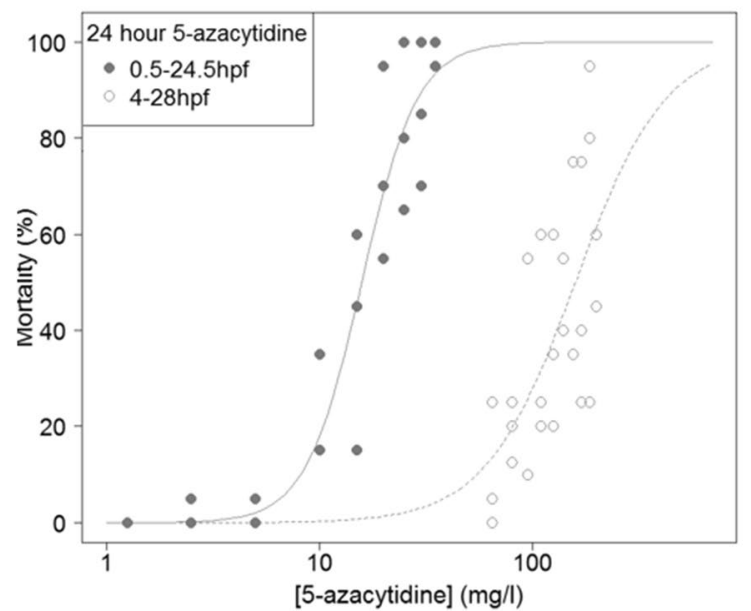

Fig. 2 Cumulative embryo mortality curves resulting from exposure to silver or 5-azacytidine. Comparisons between mortality curves for a silver exposures initiated at 0.5 and $4 \mathrm{hpf}$, after $24 \mathrm{~h}$ of exposure, b silver exposures initiated at 0.5 and $4 \mathrm{hpf}$, after $48 \mathrm{~h}$ of exposure, c 5 -azcytidine exposures initiated at 0.5 and $4 \mathrm{hpf}$, after $24 \mathrm{~h}$ of exposure and d 5-azacytidine exposures initiated at 0.5 and $4 \mathrm{hpf}$, after

initiation of ZGA) when mortality was assessed at $24 \mathrm{~h}$ after the initiation of the exposure (Fig. 2a, $p=0.0227$; Table 2), but the increase in toxicity was small. LC50 concentrations derived from the drc model were $29 \mu \mathrm{g} / \mathrm{L} \mathrm{Ag}^{+}$ for the exposure period commencing at $0.5 \mathrm{hpf}$, and $35 \mu \mathrm{g} / \mathrm{L}$ $\mathrm{Ag}^{+}$for the 4-52 hpf exposure period (nominal concentrations; Table 3) corresponding to an increase in toxicity of 1.2-fold. A significant interaction between exposure period and toxicity was also recorded, where the exposure initiated at $0.5 \mathrm{hpf}$ caused a steeper mortality curve than exposure initiated at $4 \mathrm{hpf}$ (Fig. 2a and b, $p=0.0119$ and 0.0243 for mortality data collected $24 \mathrm{~h}$ and $48 \mathrm{~h}$ after the onset of the (b)

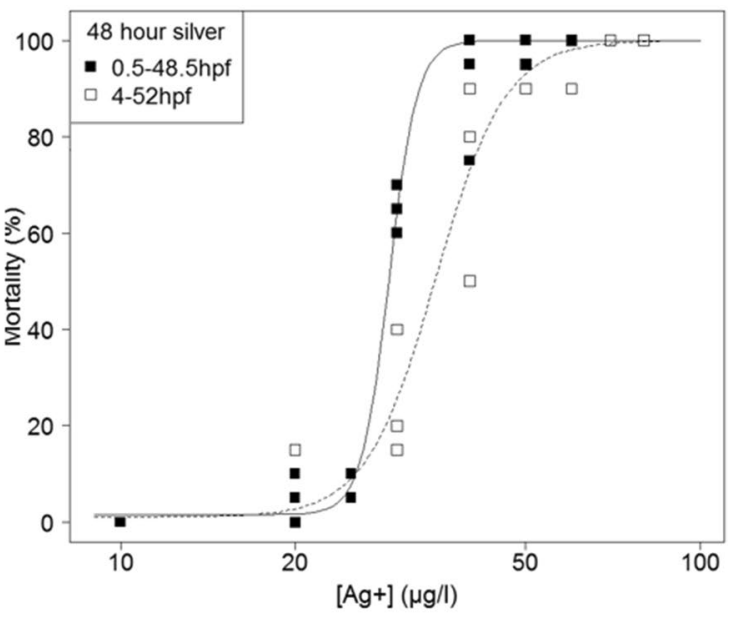

(d)



$48 \mathrm{~h}$ of exposure. Each point represents the percentage of mortality in one replicate dish containing 20 embryos, with three independent replicates per exposure concentration. A dose-response model with four-parameter log-logistic function was fitted to produce each curve in $\mathrm{R}$ using the drc package. Statistical analysis of the difference between mortality curves at each exposure period are given in Table 2

exposure; Table 2). In addition, we compared the mortality data obtained for $24 \mathrm{~h}$ and $48 \mathrm{~h}$ to assess whether mortalities increased progressively over time. Mortality continued to increase after $24 \mathrm{~h}$ of exposure and was significantly greater at $48 \mathrm{~h}$ compared to $24 \mathrm{~h}$ both for exposures initiated at 0.5 and $4 \mathrm{hpf}$ ( $p=0.019$ and 0.00021 for exposures initiated at 0.5 and 4 hpf, respectively; Fig. S1a and b; Table S1).

The developmental stage at which exposures were initiated caused pronounced significant differences in toxicity to 5 -azacytidine after 24 and $48 \mathrm{~h}$ of exposure (Fig. $2 \mathrm{c}$ and d; Table 2). Greater toxicity was recorded for exposures initiated at 1 -cell stage $(0.5 \mathrm{hpf})$, compared to exposures 
Table 2 Analysis of variance models for the relationships between exposure concentrations, time at which exposures were initiated $(0.5$ or $4 \mathrm{hpf}$ ) and the interaction between the two variables

\begin{tabular}{|c|c|c|c|c|c|c|}
\hline \multicolumn{7}{|c|}{ ANOVA } \\
\hline & \multicolumn{2}{|c|}{ Concentration } & \multicolumn{2}{|c|}{$\begin{array}{l}\text { Exposure initiation }(0.5 \text { or } \\
4 \mathrm{hpf})\end{array}$} & \multicolumn{2}{|c|}{ Interaction } \\
\hline & $F$ & $p$ & $F$ & $p$ & $F$ & $p$ \\
\hline \multicolumn{7}{|c|}{ (a) Silver } \\
\hline $24 \mathrm{~h}$ & 198.582 & $<2 \mathrm{e}-16^{* * * *}$ & 5.580 & $0.0227 *$ & 6.884 & $0.0119^{*}$ \\
\hline $48 \mathrm{~h}$ & 211.925 & $<2 \mathrm{e}-16^{* * *}$ & 2.592 & 0.1146 & 5.443 & $0.0243 *$ \\
\hline \multicolumn{7}{|c|}{ (b) 5-azacytidine } \\
\hline $24 \mathrm{~h}$ & 14.64 & $0.000335 * * *$ & 64.14 & $8.43 \mathrm{e}-11 * * *$ & 114.31 & $4.81 \mathrm{e}-15^{* * *}$ \\
\hline $48 \mathrm{~h}$ & 35.47 & $1.90 \mathrm{e}-07 * * *$ & 42.81 & $2.11 \mathrm{e}-08 * * *$ & 81.17 & $2.04 \mathrm{e}-12 * * *$ \\
\hline
\end{tabular}

Zebrafish embryos were exposed to (a) silver or (b) 5-azacytidine and mortality was recorded after 24 and $48 \mathrm{~h}$ of exposure. The resulting $F$ and $p$ values are shown for each model. (Significance codes: ${ }^{*} p<0.05$, * $* p<0.01, * * * p<0.001)$. Graphical depictions of data shown in Fig. 2

\begin{tabular}{|c|c|c|c|c|}
\hline \multirow{2}{*}{$\begin{array}{l}\text { Proportion of mortality } \\
\text { after } 48 \text { h exposure }(\%)\end{array}$} & \multicolumn{2}{|c|}{ Silver LC $(\mu \mathrm{g} / \mathrm{L}) \pm \mathrm{SEM}$} & \multicolumn{2}{|c|}{ 5-azacytidine $\mathrm{LC}(\mathrm{mg} / \mathrm{L}) \pm \mathrm{SEM}$} \\
\hline & $0.5-48.5 \mathrm{hpf}$ & $4-52 \mathrm{hpf}$ & $0.5-48.5 \mathrm{hpf}$ & 4-52 hpf \\
\hline LC10 & $25.722 \pm 1.273$ & $25.823 \pm 1.662$ & $7.857 \pm 1.782$ & $46.612 \pm 12.401$ \\
\hline LC20 & $26.905 \pm 0.950$ & $28.878 \pm 1.403$ & $9.922 \pm 1.710$ & $64.629 \pm 12.832$ \\
\hline LC50 & $29.056 \pm 0.419$ & $34.962 \pm 1.013$ & $14.787 \pm 1.425$ & $112.997 \pm 11.994$ \\
\hline LC90 & $32.822 \pm 1.135$ & $47.336 \pm 2.300$ & $27.828 \pm 3.975$ & $273.929 \pm 49.337$ \\
\hline
\end{tabular}

Lethal concentrations were determined from the dose-response models with four-parameter log-logistic function ran in $\mathrm{R}$ using package drc, and based on nominal chemical concentrations
Table 3 Comparison of the lethal concentrations (LC) \pm standard error of the mean following exposure of zebrafish embryos to silver and 5 -azacytidine for $48 \mathrm{~h}$, initiated at 0.5 or $4 \mathrm{hpf}$ (one-cell stage or sphere stage, respectively) initiated at sphere stage ( $4 \mathrm{hpf}$ ) (Fig. $2 \mathrm{c}$ and d, $p=8.43 \mathrm{e}-11$ and $2.11 \mathrm{e}-08$ for $24 \mathrm{~h}$ and $48 \mathrm{~h}$ of exposure, respectively), with over sevenfold increase in LC50 concentrations for the later exposure period after $48 \mathrm{~h}$ exposure (from 14.787 to $112.997 \mathrm{mg} / \mathrm{L}$; nominal concentrations; Table 2). A significant interaction between exposure period and toxicity was also recorded, where $0.5-48.5 \mathrm{hpf}$ exposure caused steeper $0-100 \%$ mortality curve than exposures between 4 and $52 \mathrm{hpf}$ (Fig. 2d, $p=2.04 \mathrm{e}-12$ ). There was no significant increase in embryo mortality after $24 \mathrm{~h}$ of exposure when exposures were initiated at $0.5 \mathrm{hpf}$ (Fig. S1c, $p=0.47$; Table S1), but mortality continued to increase in exposures initiated at $4 \mathrm{hpf}$, with a significant difference between mortality curves for 4-28 hpf and 4-52 hpf (Fig. S1d, $p=0.0082$; Table S1).

\section{Influence of pre-exposure to silver during early development on the susceptibility of larvae upon re-exposure}

At $72 \mathrm{hpf}$, embryos exposed to $30 \mu \mathrm{g} / \mathrm{L} \mathrm{Ag}^{+}$for $24 \mathrm{~h}$ (initiated either at 0.5 or $4 \mathrm{hpf}$ ) showed a mortality rate below $20 \%$ (Fig. 3). Embryo mortality by $72 \mathrm{hpf}$ was significantly different between control groups and embryos exposed to silver from 0.5 hpf (Fig. 3, $p=0.037$ ), but not for those exposed from 4 hpf (Fig. 3, $p=0.596$ ). Upon re-exposure, the percentage of mortality in exposed embryos increased significantly compared to those maintained in control conditions (Fig. 3, $p=0.017$ ), but pre-exposure did not cause an alteration in cumulative mortality upon re-exposure, despite the fact that around 20\% mortality had occurred in pre-exposed groups before re-exposure (Fig. 3, $p=0.223$ ). Interestingly, for naïve embryos, silver toxicity was greater following $24 \mathrm{~h}$ of exposure when exposures were initiated after hatching (72 hpf) compared to those exposed during early development (Fig. 3, $p=0.014$ ).

\section{Transcript profiling}

No differences in gene transcription were recorded between embryo pools kept in control conditions and those exposed to $25 \mu \mathrm{g} / \mathrm{L} \mathrm{Ag}^{+}$or $7.85 \mathrm{mg} / \mathrm{L} \mathrm{5-azacytidine} \mathrm{(nominal} \mathrm{con-}$ centrations) for $0.5-48.5 \mathrm{hpf}$ or $4-52 \mathrm{hpf}$ for any of the gene transcription profiles studied (Fig. 4).

\section{Discussion}

In this study, we aimed to determine whether silver toxicity was influenced by developmental stage of zebrafish, and whether pre-exposure to silver during early development caused long-lasting alterations in the susceptibility of 


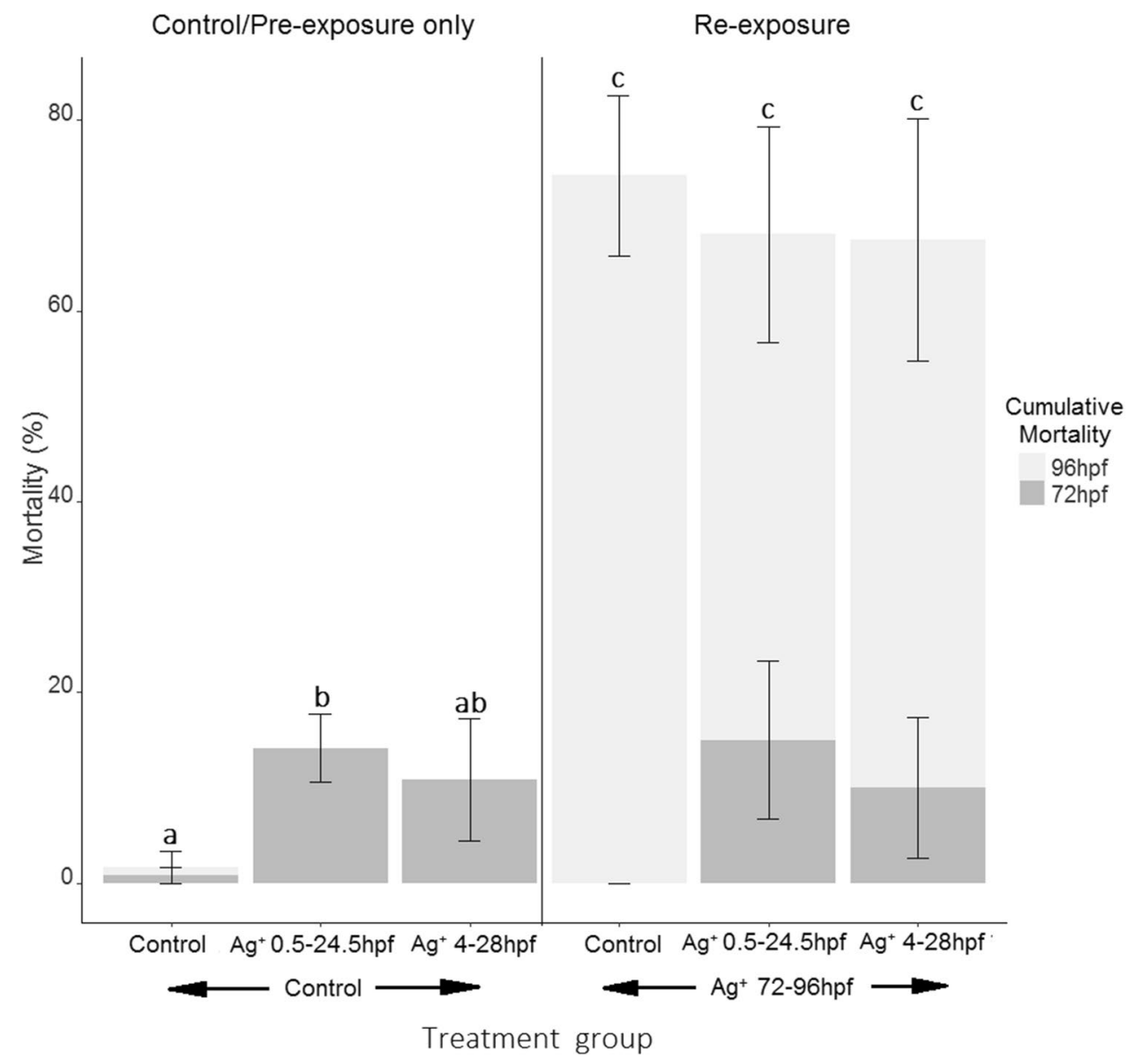

Fig. 3 Cumulative percentage of mortality following exposure and re-exposure of embryos to silver after $72 \mathrm{hpf}$ (dark grey) and $96 \mathrm{hpf}$ (light grey). The first three bars describe mortality in embryos that were either kept in control conditions until $96 \mathrm{hpf}$; exposed to $30 \mathrm{ug} / \mathrm{L} \mathrm{Ag}^{+}$from 0.5 to $24.5 \mathrm{hpf}$; or exposed from 4 to $28 \mathrm{hpf}$. All three groups were then kept in control conditions until $96 \mathrm{hpf}$, with mortality assessed at $72 \mathrm{hpf}$ (dark grey) and $96 \mathrm{hpf}$ (light grey). The second three bars show mortality upon re-exposure at $72 \mathrm{hpf}$. Embryos were kept in control conditions or exposed to silver during early development and subsequently kept in clean medium until $72 \mathrm{hpf}$, as described for the previous three groups. Mortality was

larvae to subsequent exposures. We report that exposures initiated at the one-cell stage, and including the processes of epigenetic reprogramming and chorion hardening, caused greater toxicity than those initiated later in development. However, exposures to silver during early development did not affect the susceptibility of larvae during subsequent exposures under our experimental conditions. These findings are important to inform on the design of testing systems for chemical risk assessment using embryo models. assessed at $72 \mathrm{hpf}$ (dark grey), then all three groups were re-exposed to $30 \mathrm{ug} / \mathrm{L} \mathrm{Ag}^{+}$for $24 \mathrm{~h}$ prior to mortality assessment at $96 \mathrm{hpf}$ (light grey). Treatment exposure groups indicate the conditions during each exposure period, with $n=6$ biological replicates per treatment. Significant differences for $96 \mathrm{hpf}$ cumulative mortality were determined using a Kruskal-Wallis rank-sum test, and significant pairwise differences between control, pre-exposed and re-exposed groups were determined using a Wilcoxon rank-sum test. Significant pairwise differences between treatment groups are notated by letter differences above each bar when $p<0.05$

\section{Methylation inhibitor 5-azacytidine is significantly more toxic to zebrafish embryos when exposures include the epigenetic reprogramming period}

We have identified a dramatic increase in toxicity (over sevenfold) for 5-azacytidine when exposures were initiated at one-cell stage ( $0.5 \mathrm{hpf})$ during zebrafish embryo development compared to exposures initiated during sphere stage, and after the period of epigenetic reprogramming. Embryo mortality continued to increase between 24 and $48 \mathrm{~h}$ for exposures initiated at $4 \mathrm{hpf}$, but no further mortalities were observed after $24 \mathrm{~h}$ for exposures initiated at $0.5 \mathrm{hpf}$. This may be due to its toxicity during early development when 5 -azacytidine prevents re-methylation from occurring 
(a)

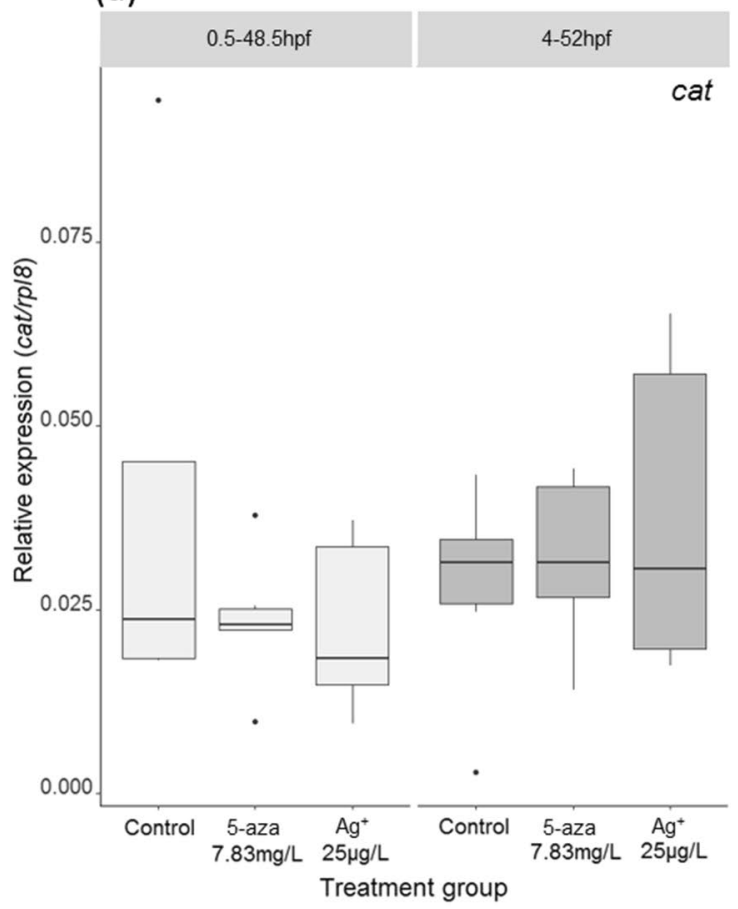

(c)

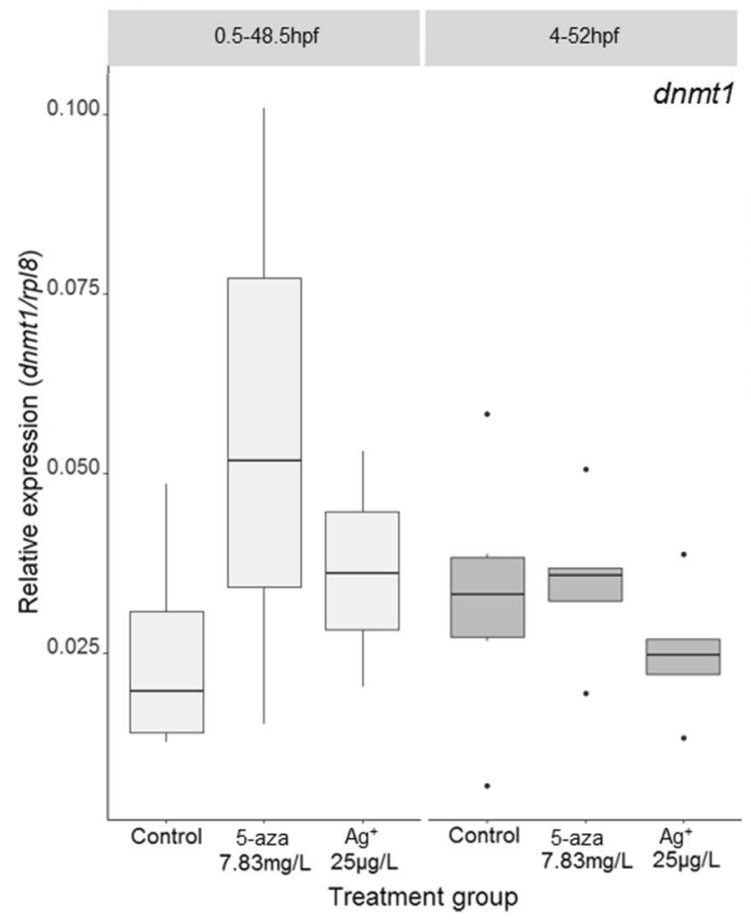

Fig. 4 Transcript profiles for catalase (cat), metallothionein $2(m t 2)$, DNA (cytosine-5-)-methyltransferase 1 (dnmt1) and DNA (cytosine-5-)-methyltransferase $3 b b .2$ (dnmt3bb.2) following exposure of zebrafish embryos to 5-azacytidine (abbreviated as 5-aza) and silver (added in the form of silver nitrate, $\mathrm{Ag}^{+}$) during the exposure period $0.5-48.5$ hpf or 4-52 hpf. Embryo pools ( $n=20$ embryos per pool) were exposed to $7.83 \mathrm{mg} / \mathrm{L}$ 5-azacytidine or $25 \mu \mathrm{g} / \mathrm{L} \mathrm{Ag}^{+}$. Relative expression was plotted for each embryo pool $(n=3-6$ pools depend- (b)

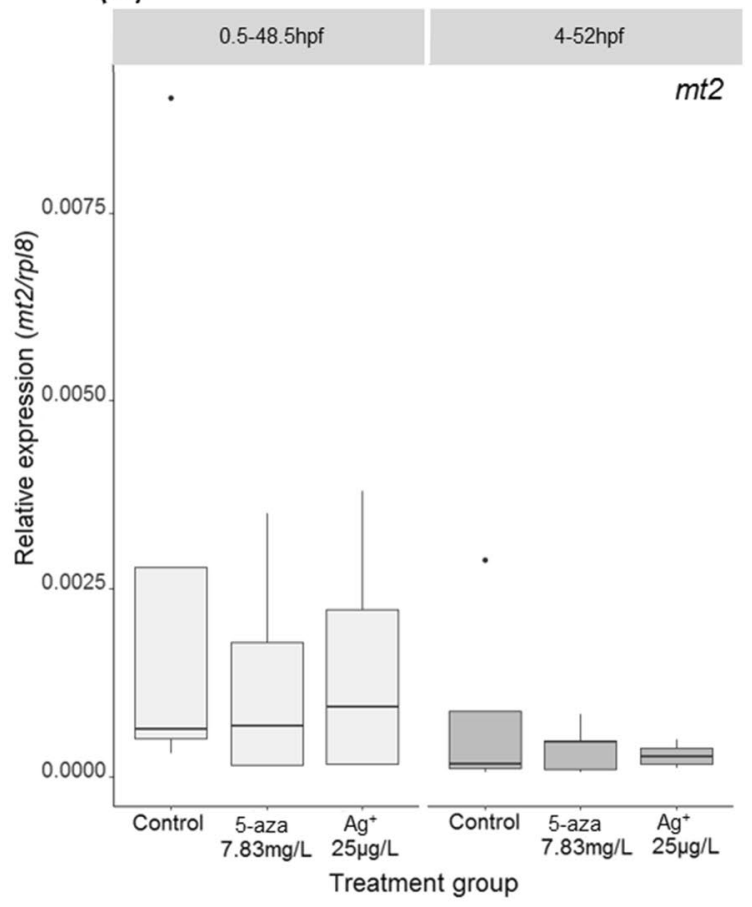

(d)

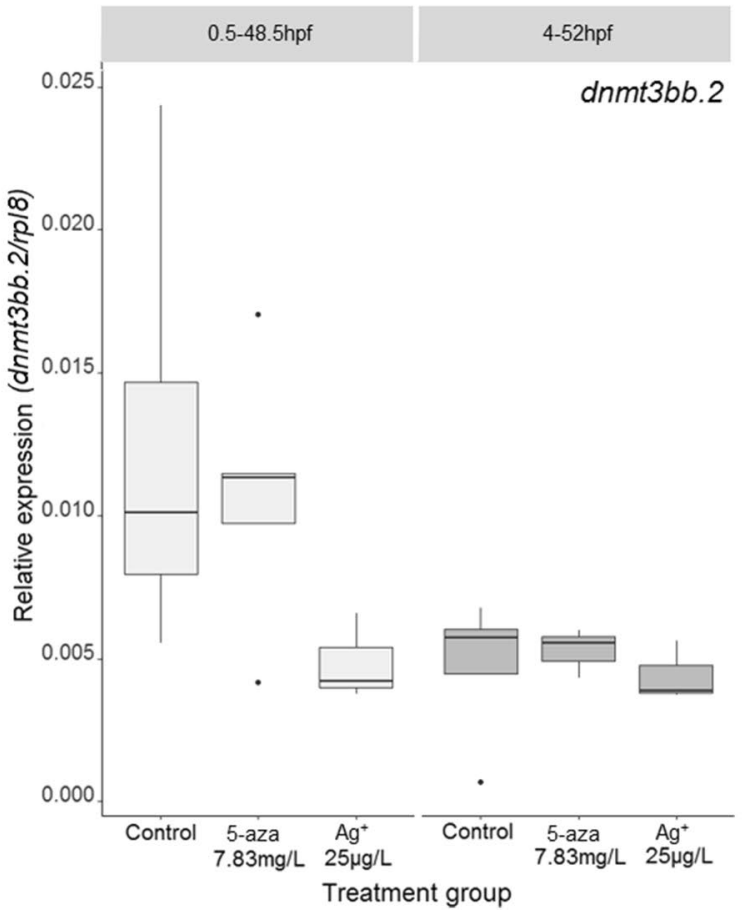

ing on the treatment group) using rpl8 as a control gene. The Chauvenet's criterion was applied prior to statistical analysis to remove outliers from the data. Statistics were carried out within each chemical treatment using a one way ANOVA or Kruskal-Wallis rank-sum test (depending on whether data was normally distributed). There were no significant differences between treatment groups for any of the gene transcription profiles studied 
(Taylor and Jones 1982), and when embryos were most sensitive to this chemical. After $24 \mathrm{hpf}$, as its toxicity is greatly reduced, the exposure concentration is no longer sufficient to cause adverse effects at this later stage. These data corroborate the findings of Martin et al. who reported that 5 -azacytidine exposure before the mid-blastula transition results in greater toxicity with over $20 \%$ of embryos showing abnormal phenotypes, but when exposures start from $3 \mathrm{hpf}$ and from $6 \mathrm{hpf}$, this results in 11\% and 2\% abnormal phenotypes, respectively (Martin et al. 1999). Similar levels of 5-azacytidine toxicity were reported in zebrafish embryos whether the chorion had been removed before exposure or not (Martin et al. 1999), indicating that chorion permeability may not be a factor affecting 5-azacytidine toxicity. During the initial stages of zebrafish development, key cell and organ pathways are being established (Kimmel et al. 1995) and from the 16-cell stage, the epigenome of the newly formed zygote is in the process of genome-wide demethylation to remove gamete-specific methylation, followed by de novo methylation to produce an embryo-specific epigenome (Jiang et al. 2013). We hypothesise that this period of widespread de novo methylation is particularly sensitive to environmental stressors, especially those that have the potential to modify the methylome. 5-azacytidine has been shown to become incorporated into DNA and RNA, inhibiting methylation and activating specific gene regions by limiting DNA methyltransferase (dnmt) activity (Christman 2002). This occurs as methyltransferases irreversibly bind to 5-azacytidine residues in DNA (Taylor and Jones 1982), and this chemical is often used in the treatment of cancers where $\mathrm{CpG}$ islands have become methylated, inducing tumour development (Christman 2002). 5-azacytidine has been shown to mainly impact exogenous methylation including environmentally caused alterations (Bird 1992), causing global demethylation in zebrafish embryos (Bouwmeester et al. 2016; Kamstra et al. 2015a) and altered methylation sites involved in embryonic development including gastrulation and dorsal mesoderm patterning (Martin et al. 1999; Kamstra et al. 2017). Alterations to cardiomyocyte proliferation and apoptosis have also been reported in exposed zebrafish embryos, indicating widespread developmental deformities during early development exposure (Yang et al. 2019), and highlighting how 5-azacytidine demethylation is non-specific (Ceccaldi et al. 2011). Methyltransferases are of vital importance during epigenetic reprogramming (Wang and Bhandari 2019), so we propose that the dramatic increase in toxicity of 5-azacytidine observed in this study was due to the vulnerability of the methylome during early development to de novo methylation inhibition, leading to large-scale consequences to cell and organism viability. The later exposure period in this study was initiated after the somatic epigenetic reprogramming period was mostly complete (Jiang et al. 2013; Potok et al. 2013), and we predict that the epigenome is less vulnerable to disruption outside of this period. However, tissue-specific methylomes may still be affected after this period.

Investigation of some potential mechanisms of toxicity using quantitative PCR to measure target gene transcription resulted only in inconclusive results and failed to advance our understanding on how 5-azacytidine affects the embryos within our experimental setting. This could be due to multiple factors, including our choice of concentration (below that causing mortality even under the most sensitive exposure conditions), length of exposure and choice of target genes. A more comprehensive analysis using global transcription measurements, as well as an experimental design including more doses and time points, would be required to fully elucidate this question.

The exposure scenario we have designed, which included or excluded the period of epigenetic reprogramming during zebrafish embryo development, could allow for the screening and identification of chemicals that disrupt the epigenome. We hypothesise that chemicals that show greater toxicity when exposures occur during the epigenetic reprogramming period as opposed to after reprogramming and for which it is possible to demonstrate no variation in uptake dynamics are likely to disrupt the epigenome, as seen here for 5-azacyitidine. Therefore, we propose that this method could be developed to become a screening tool to identify chemicals of concern for epigenetic effects.

\section{Development stage at which exposures to silver are initiated determines their toxicity for zebrafish embryos}

We observed a greater toxicity following silver exposures initiated at the one-cell stage compared to those initiated at blastula stage, although the differences in toxicity were far less pronounced than for 5-azacytidyne. These differences were small but very consistent across experiments (a similar difference in toxicity was also observed during the re-exposure experiments in which the first exposure caused greater mortality for embryos exposed during the earlier developmental period). Similarly, greater silver toxicity was reported for exposures initiated earlier in embryogenesis in a comparison of exposures initiated at 2, 4 and 6 hpf by 1.89 fold (2-4 hpf) and 1.13-fold (4-6 hpf), respectively (Groh et al. 2015). The continued increase in mortality across the $48 \mathrm{~h}$ exposure period indicates that susceptibility to silver increases in older embryos and this is corroborated by the differences in toxicity observed during the re-exposure periods (where exposures during the first day of development caused far less mortality than those conducted after hatching).

We propose three hypotheses that may explain the differences in toxicity encountered during early development. 
First, during early development the chorion is more permeable, as the embryo takes up water due to changes in osmotic pressure after fertilisation (Peterson and Martin-Robichaud 1982). This process has been reported to last for several hours, which could allow certain toxicants to reach embryo cells more readily, thus increasing their toxicity. Second, the embryo genome is not activated until the mid-blastula stage (Bertoldo et al. 2015), therefore, the embryo cannot successfully deploy defence mechanisms involving de novo transcription until this point. Finally, the epigenetic reprograming takes place during the first phases of embryogenesis, up to the mid-blastula stage (Jiang et al. 2013; Potok et al. 2013), and we hypothesise that organisms are more susceptible to disruption of the epigenome by environmental stressors during this highly dynamic period. All of these processes occur predominantly before $4 \mathrm{hpf}$, and either individually or in combination may explain the differences in toxicity observed.

The chorion has been shown to protect embryos during the first few days of development from a number of environmental stressors, abiotic and biotic in nature (Van Leeuwen et al. 1985; Gellert and Heinrichsdorff 2001). However, due to large changes in osmotic pressure that occur once an oocyte is spawned, the chorion swells during the first few hours of development, filling the perivitelline space through water absorption, creating a colloidal suspension of proteins (Peterson and Martin-Robichaud 1982). The increased permeability of the chorion during this time allows some chemicals to be taken up through the membrane more easily (Jezierska et al. 2009), through pores 0.6-0.7 $\mu \mathrm{m}$ wide (Kim and Tanguay 2014) or via endocytosis, as Chen et al. showed for graphene oxide at $2 \mathrm{hpf}$ (2017). Therefore, the increase in silver toxicity observed in our study for embryos exposed earlier in development may be due to an increase in silver ions able to reach the embryo. Böhme et al. reported the presence of silver within the perivitelline space and throughout the embryo tissue when $>30 \mu \mathrm{g} / \mathrm{L}$ exposures began at 2 hpf (Böhme et al. 2015), and Cunningham reported no difference in silver bioaccumulation in zebrafish embryo tissue exposed from $2 \mathrm{hpf}$ that had had their chorion removed to those with intact chorions (Cunningham et al. 2013). These results further attest to the notion that increased toxicity is due, at least in part, to increased silver concentrations within embryo tissues, due to chorion permeability during the first few hours of development.

Second, we hypothesised that the greater toxicity observed for exposures initiated at the one-cell stage could be due to the fact that zygotic genome activation in zebrafish does not occur until the mid-blastula stage. Before this, the embryo is largely guided by maternal gene products with synchronous cellular divisions (O'Boyle et al., 2007). It is hypothesised that transcription does not occur automatically in early developmental stages because of a lack of transcription factors and machinery, maternally loaded repressors, tightly packed chromatin and short cell cycle lengths (reviewed in Pálfy et al. 2017). Before maternal-tozygotic transition, maternal transcripts and the regulation of translation from these transcripts, as well as regulation of protein function are the main tools for stress response in early-stage embryos (reviewed in Schulz and Harrison 2019). If the mother was exposed to the same toxicant, maternal transcripts and other factors may also include those important for the response to such a stressor that could improve survival (Plautz and Salice 2013), but this was not the case in our study. Although some regulation can occur prior to ZGA, it is far more efficient once cells can respond with rapid gene transcription to control mRNA translation (de Nadal et al. 2011). Genome activation likely plays an important role in embryo response to environmental stressors, and could be an explanation for the increase in toxicity to silver observed in our study during the earlier exposure period.

Our final hypothesis to explain the greater toxicity recorded for exposures initiated at the 1-cell stage proposes that the vulnerability of the epigenome to environmental stressors during reprogramming may explain, at least in part, the effects seen. Epigenetic alterations have been documented following environmental stressor exposure, including for silver ( Xu et al. 2018; Tai et al. 2019). Despite this, epigenetic alterations are not included in most chemical risk assessments (Mirbahai and Chipman 2014). From 16-cell to mid-blastula stage, widespread demethylation and de novo methylation occur across the genome to create a consistent zygote epigenome from the two parental germ cell genomes (Jiang et al. 2013; Potok et al. 2013; discussed above). Kamstra et al. highlight how important this time period is when studying environmental stressors as epigenetic modifications at this point could lead to negative adult phenotypes (Kamstra et al. 2015b), and the sensitivity of this period has been studied in mammalian systems (reviewed in Bertoldo et al. 2015). Zebrafish embryo exposure to copper during this period caused significant upregulation of 6 dnmt 3 isoforms and $m t 2$ (Dorts et al. 2016), and an upregulation of DNA and histone methyltransferases were observed following Atlantic cod embryo exposure to mine tailings waste (Reinardy et al. 2019). Although our study found zebrafish embryos were more sensitive to silver when the exposure window encompassed the period of epigenetic reprogramming, it is important to note that the magnitude of this difference was modest and far less than that observed for 5-azacytidine (1.2fold compared to 7.6-fold). Therefore, we hypothesise that disruption of epigenetic pathways may contribute to the differences in silver toxicity observed, but to a far lesser extent than that observed for 5-azacytidyne.

To explore some of the potential mechanisms responsible for the differences in silver toxicity observed, we conducted 
transcriptional analysis of some gene biomarkers for metal toxicity (cat and $m t 2$ ) and DNA methylation (dnmt 1 and $d n m t 3 b b .2)$. No significant alterations in transcription were observed for any of the genes tested during either exposure period, similarly to that observed for the positive control 5 -azacytidine, discussed above. The lack of alterations in transcription measured in our study could be due to a number of reasons, including the concentration tested $(25 \mu \mathrm{g} / \mathrm{L}$ $\mathrm{Ag}^{+}$), which was below that required to cause mortality and may be insufficient to cause measurable alterations in the transcription of these biomarkers under our exposure conditions. In previous studies, a recovery from silver toxicity at the transcriptional level at $48 \mathrm{hpf}$ was observed compared to earlier time points (van Aerle et al. 2013) suggesting that the lack of significant alterations observed in our study could be associated with a similar recovery process. Boyle and Goss indicated that exposure from 24-48 hpf did not cause significant metallothionein regulation, but $24 \mathrm{~h}$ exposures initiated at 72 or $96 \mathrm{hpf}$ resulted in measurable upregulation, indicating that time since exposure initiation and developmental stage are both important factors determining transcriptional responses in a similar experimental system (Boyle and Goss 2018). Further, the lack of statistically significant effects could be due to the relatively large variability encountered, and the fact that whole body homogenates were analysed. Whole-body transcription measurements can mask individual cell transcription alterations, either through cell composition changes resulting from toxicant exposure or variation in individual cell response. Parsons et al. highlighted the effect of brominated flame retardants on developing zebrafish was both tissue- and developmental-stage-specific, but harder to detect in whole-body homogenates (Parsons et al. 2019). Finally, the target genes that were chosen for investigation may not have been altered by the exposure, but other genes and pathways may have been altered. Therefore, presence of transcriptional responses for other genes cannot be ruled out.

We demonstrate a greater toxicity for earlier exposures and propose three potential mechanisms that alone or in combination may be responsible for this observation, including chorion permeability, incomplete development of defence pathways due to an inactivated zygote genome, and epigenetic alterations, and more mechanistic studies are required to elucidate the contribution of each of these hypothesis to the alterations in toxicity reported here. Our observations demonstrate the fundamental importance of considering the time of exposure initiation when determining consequences of toxicant exposure for wild populations. In an environmentally realistic exposure scenario, gametes and embryos come into contact with toxicants immediately after they are released into the water column, so understanding sensitivity during the initial stages of development is imperative.

\section{Pre-exposure to silver during early development does not influence the susceptibility of zebrafish larvae upon re-exposure}

We have observed no differences in mortality between naïve and pre-exposed zebrafish larvae when they were re-exposed to silver after hatching. This was the case independent of the exposure window during which embryos were pre-exposed to silver (initiated at the 1-cell stage or after epigenetic reprogramming), despite the greater toxicity observed for the earlier exposure window of 0.5-24.5 hpf. However, silver was significantly more toxic for exposures initiated at 72-96 hpf compared to those initiated at 0.5 or $4 \mathrm{hpf}$. An increase in sensitivity in hatched larvae was also reported by Böhme et al. for dechorinated 26-74 hpf embryos that were more sensitive to silver than 2-50 hpf chorinated embryos (Böhme et al. 2015), and has been observed for other metals, such as copper (Fitzgerald et al. 2016).

There are few reports in the literature addressing the influence of metal pre-exposure on subsequent tolerance to further exposure. Alterations in tolerance, whether due to physiological or molecular differences, can improve plasticity and have been hypothesised to lead to genetic assimilation (Badyaev 2005). Repeated exposures to copper, an essential metal, showed that two pulsed $24 \mathrm{~h}$ exposures at 24 and $72 \mathrm{hpf}$ caused the same effects as a continuous $96 \mathrm{~h}$ exposure in zebrafish embryos, despite the shorter total exposure duration (Boyle et al. 2020), whereas pre-exposures to carbon tetrachloride increased tolerance to normally lethal doses in rats (Dambrauskas and Cornish 1970). Adult fish have shown increased tolerance to copper following a period of acclimation (Anadu et al. 1989), and this has been attributed to increased metallothionein expression (Bradley et al. 1985).

Our results indicate a lack of long-lasting memory in embryo cells, despite the disruption that the initial exposure inevitably had caused (demonstrated by the significant increase in mortality observed for the earlier pre-exposure group). Memory and, thus, altered response to a stressor can occur through a number of biological routes. Physiologically, cells produce proteins to respond to stressors, such as those involved in the storage or excretion of toxic chemicals (Kägi and Schäffer 1988), that can decrease response time if exposures are frequent, thereby preventing some of the toxicity. This has been shown in yeast in response to repeated salt exposure (Guan et al. 2012) and in mice, where exposure to steroids caused a significant increase in myonuclei three months after removal of the drug (Egner et al. 2013). Although protein translation in response to initial exposure is likely to have occurred, it is possible that these effects were not long-lasting or protective in our experimental system, as no increase in tolerance upon re-exposure to silver was observed. Metallothionein and other proteins 
active during exposure to metals have been shown to return to control concentrations in cells after a depuration period in correlation with exposure concentration (Alvarado et al. 2005). This is also supported by the observation that transcript profiles after a $48 \mathrm{~h}$ exposure to silver at the LC10 concentration were unaltered in our study.

Alterations in epigenetic gene regulation result in longlasting memory within cells that can alter response to subsequent exposures independently or in conjunction with physiological effects. For example, after 14 days depuration from exposure to copper, zinc or cadmium, upregulation of metallothionein was still recorded in zebrafish gills even at exposure concentrations as low as $1 \mathrm{ppm}$ (Alvarado et al. 2006). Silver could also accumulate within the embryo, particularly during the exposures initiated before chorion hardening as shown by Böhme et al. (2015), leading to embryos being exposed to a higher concentration of silver than naïve embryos upon secondary exposure, although chemical analysis would be needed to determine this. As no alteration in tolerance was observed, epigenetic alterations with consequences for susceptibility to silver are unlikely to play a major role under our experimental conditions.

Physiological and gene transcription effects are likely to have occurred to some degree during silver pre-exposure, as an increase in mortality was observed (significant for the embryos exposed from one-cell stage). Proportionally, a higher percentage of naïve embryos died during the 72-96 hpf exposure period than in pre-exposed groups that were re-exposed, although the total cumulative mortality by $96 \mathrm{hpf}$ was not significantly different between groups. We hypothesise that the threshold for mortality during the second exposure was likely dictated by potential genetic differences between individuals. There is genetic variation even within laboratory strains of zebrafish (Coe et al. 2009), and we theorise that this variation causes individuals to be more or less resistant to stressors, and this variability may explain the threshold for mortality encountered after the second exposure that was common across all exposed groups.

Our observations support that exposure to silver during zebrafish embryo development, even when exposure occurs at a time of increased sensitivity, does not result in alteration of tolerance under our experimental conditions. This does not preclude the possibility that silver exposure may cause long-lasting effects or even induce differential susceptibility under different exposure conditions or for different species, and our study has the limitation of considering only one exposure duration and one concentration. However, an absence of increased tolerance to silver upon re-exposure indicates that epigenetic alterations during the reprogramming period are unlikely, and increased toxicity after embryo hatching and before chorion hardening point to chorion permeability as the primary determinant of embryo sensitivity to silver.

\section{Conclusion}

In conclusion, we demonstrated that periods of sensitivity for silver exposure exist during zebrafish embryo development, when exposures are initiated prior to reprogramming, ZGA and chorion hardening. These three processes, alone or in combination, may be responsible for the enhanced susceptibility of zebrafish embryos to silver exposure during early development, and the evidence we present points towards chorion permeability being the most important factor. We report no alteration in susceptibility to silver following preexposure under our experimental conditions, independently of whether the initial exposure occurred during the most sensitive period. Our data illustrate the importance of considering how susceptibility to chemical exposure varies during early development in the design of testing systems for chemical risk assessment using embryo models.

Acknowledgements We thank Gregory Paull and the Aquatic Resources Centre at the University of Exeter for zebrafish husbandry support.

Funding This work is funded by a Natural Environmental Research Council iCASE Ph.D studentship (Grant No. NE/P010261/1) and the Centre for Environment, Fisheries and Aquaculture Science.

\section{Compliance with ethical standards}

Ethical approval All procedures performed in studies involving animals were in accordance with the ethical standards of the institution at which the studies were conducted. The datasets generated during the current study are available from the corresponding author on reasonable request.

Open Access This article is licensed under a Creative Commons Attribution 4.0 International License, which permits use, sharing, adaptation, distribution and reproduction in any medium or format, as long as you give appropriate credit to the original author(s) and the source, provide a link to the Creative Commons licence, and indicate if changes were made. The images or other third party material in this article are included in the article's Creative Commons licence, unless indicated otherwise in a credit line to the material. If material is not included in the article's Creative Commons licence and your intended use is not permitted by statutory regulation or exceeds the permitted use, you will need to obtain permission directly from the copyright holder. To view a copy of this licence, visit http://creativecommons.org/licenses/by/4.0/.

\section{References}

Alvarado NE et al (2005) Cellular biomarkers of exposure and biological effect in hepatocytes of turbot (Scophthalmus maximus) exposed to $\mathrm{Cd} \mathrm{Cu}$ and $\mathrm{Zn}$ and after depuration. Aquat Toxicol 74(2):110-125. https://doi.org/10.1016/j.aquatox.2005.03.024

Alvarado NE et al (2006) Quantitative changes in metallothionein expression in target cell-types in the gills of turbot (Scophthalmus maximus) exposed to $\mathrm{Cd} \mathrm{Cu}, \mathrm{Zn}$ and after a depuration 
treatment. Aquat Toxicol 77(1):64-77. https://doi.org/10.1016/j. aquatox.2005.10.017

Anadu DI et al (1989) Effect of zinc exposure on subsequent acute tolerance to heavy metals in rainbow trout. Bull Environ Contam Toxicol 43(3):329-336. https://doi.org/10.1007/BF01701865

Artemov AV et al (2017) Genome-wide DNA methylation profiling reveals epigenetic adaptation of stickleback to marine and freshwater conditions. Mol Biol Evol 34(9):2203-2213. https://doi. org $/ 10.1093 / \mathrm{molbev} / \mathrm{msx} 156$

Ashauer R, Oconnor I, Escher BI (2017) Toxic mixtures in time-the sequence makes the poison, environmental science and technology. Am Chem Soc 51(5):3084-3092. https://doi.org/10.1021/acs. est.6b06163

Badyaev AV (2005) Stress-induced variation in evolution: From behavioural plasticity to genetic assimilation. Proc R Soc B Biol Sci. https://doi.org/10.1098/rspb.2004.3045

Bertoldo MJ et al (2015) Impacts of and interactions between environmental stress and epigenetic programming during early embryo development. Reprod Fertil Dev 27(8):1125-1136. https://doi. org/10.1071/RD14049

Bird A (1992) The essentials of DNA methylation. Cell 70(1):5-8. https://doi.org/10.1016/0092-8674(92)90526-I

Böhme S et al (2015) Effect propagation after silver nanoparticle exposure in zebrafish (Danio rerio) embryos: a correlation to internal concentration and distribution patterns. Environ Sci Nano 2(6):603-614. https://doi.org/10.1039/c5en00118h

Böhme S et al (2017) Metal uptake and distribution in the zebrafish (Danio rerio) embryo: differences between nanoparticles and metal ions. Environ Sci Nano 4(5):1005-1015. https://doi. org/10.1039/c6en00440g

Bouwmeester MC et al (2016) Zebrafish embryos as a screen for DNA methylation modifications after compound exposure. Toxicol Appl Pharmacol 291:84-96. https://doi.org/10.1016/j.taap.2015.12.012

Boyle D, Goss GG (2018) Effects of silver nanoparticles in early life-stage zebrafish are associated with particle dissolution and the toxicity of soluble silver. NanoImpact 12:1-8. https://doi. org/10.1016/j.impact.2018.08.006

Boyle D, Clark NJ, Handy RD (2020) Toxicities of copper oxide nanomaterial and copper sulphate in early life stage zebrafish: effects of $\mathrm{pH}$ and intermittent pulse exposure. Ecotoxicol Environ Saf 190:109985. https://doi.org/10.1016/j.ecoenv.2019.109985

Bradley RW, DuQuesnay C, Sprague JB (1985) Acclimation of rainbow trout, Salmo gairdneri Richardson, to zinc: kinetics and mechanism of enhanced tolerance induction. J Fish Biol 27(4):367-379. https://doi.org/10.1111/j.1095-8649.1985.tb03186.x

Bury NR et al (1999) ATP-dependent silver transport across the basolateral membrane of rainbow trout gills. Toxicol Appl Pharmacol 159(1):1-8. https://doi.org/10.1006/taap.1999.8706

Campos C, Valente LMP, Fernandes JMO (2012) Molecular evolution of zebrafish dnmt 3 genes and thermal plasticity of their expression during embryonic development. Gene 500(1):93-100. https://doi. org/10.1016/j.gene.2012.03.041

Ceccaldi A et al (2011) C5-DNA Methyltransferase inhibitors: From screening to effects on zebrafish embryo development. ChemBioChem 12(9):1337-1345. https://doi.org/10.1002/cbic.201100130

Chauvenet W (1863) A manual of spherical and practical astronomy, embracing the general problems of spherical astronomy, the special applications to nautical astronomy, and the theory and use of fixed and portable astronomical instruments, with an appendix on the method of least squares. J.B. Lippincott, Philadelphia

Chen S et al (2017) Graphene quantum dot/silver nanoparticle hybrids with oxidase activities for antibacterial application. ACS Biomater Sci Eng 3(3):313-321. https://doi.org/10.1021/acsbiomate rials.6b00644

Christman JK (2002) 5-Azacytidine and 5-aza-2'-deoxycytidine as inhibitors of DNA methylation: mechanistic studies and their implications for cancer therapy. Oncogene 21(3):5483-5495. https ://doi.org/10.1038/sj.onc.1205699

Coe TS et al (2009) Genetic variation in strains of zebrafish (Danio rerio) and the implications for ecotoxicology studies. Ecotoxicology 18(1):144-150. https://doi.org/10.1007/s10646-008-0267-0

Cunningham $S$ et al (2013) Effect of nanoparticle stabilization and physicochemical properties on exposure outcome: acute toxicity of silver nanoparticle preparations in zebrafish (Danio rerio). Environ Sci Technol 47(8):3883-3892. https://doi.org/10.1021/ es303695f

Curtis LR, Seim WK, Chapman GA (1985) Toxicity of fenvalerate to developing steelhead trout following continuous or intermittent exposure. J Toxicol Environ Health 15(3-4):445-457. https://doi. org/10.1080/15287398509530671

Dambrauskas T, Cornish HH (1970) Effect of pretreatment of rats with carbon tetrachloride on tolerance development. Toxicol Appl Pharmacol 17(1):83-97. https://doi.org/10.1016/0041008X(70)90134-1

de Nadal E, Ammerer G, Posas F (2011) Controlling gene expression in response to stress. Nat Rev Genet 12:833-845. https://doi. org/10.1038/nrg3055

Dorts J et al (2016) DNA methyltransferases and stress-related genes expression in zebrafish larvae after exposure to heat and copper during reprogramming of DNA methylation. Sci Rep 6(1):34254. https://doi.org/10.1038/srep34254

Dubas ST, Kumlangdudsana P, Potiyaraj P (2006) Layer-by-layer deposition of antimicrobial silver nanoparticles on textile fibers. Colloids Surf A Physicochem Eng Asp 289(1-3):105-109. https ://doi.org/10.1016/j.colsurfa.2006.04.012

Egner IM et al (2013) A cellular memory mechanism aids overload hypertrophy in muscle long after an episodic exposure to anabolic steroids. J Physiol 591(24):6221-6230. https://doi.org/10.1113/ jphysiol.2013.264457

Fitzgerald JA et al (2016) Hypoxia suppressed copper toxicity during early development in zebrafish embryos in a process mediated by the activation of the HIF signaling pathway, Environmental Science and Technology. Am Chem Soc 50(8):4502-4512. https:// doi.org/10.1021/acs.est.6b01472

Fu C et al (2010) Ions first: $\mathrm{Na}^{+}$uptake shifts from the skin to the gills before $\mathrm{O}_{2}$ uptake in developing rainbow trout Oncorhynchus mykiss. Proc R Soc B Biol Sci 277(1687):1553-1560. https://doi. org/10.1098/rspb.2009.1545

Garcia-Reyero N et al (2015) Assessing the exposure to nanosilver and silver nitrate on fathead minnow gill gene expression and mucus production. Environ Nanotechnol Monit Manag 4:58-66. https:// doi.org/10.1016/j.enmm.2015.06.001

Gellert G, Heinrichsdorff J (2001) Effect of age on the susceptibility of zebrafish eggs to industrial wastewater. Water Res 35(15):37543757. https://doi.org/10.1016/S0043-1354(01)00084-7

Green JM et al (2018) Early life exposure to ethinylestradiol enhances subsequent responses to environmental estrogens measured in a novel transgenic zebrafish. Sci Rep 8(1):2699. https://doi. org/10.1038/s41598-018-20922-z

Groh KJ et al (2015) Critical influence of chloride ions on silver ion-mediated acute toxicity of silver nanoparticles to zebrafish embryos. Nanotoxicology 9(1):81-91. https://doi. org/10.3109/17435390.2014.893379

Guadagnolo CM, Brauner CJ, Wood CM (2001) Chronic effects of silver exposure on ion levels, survival, and silver distribution within developing rainbow trout (Oncorhynchus mykiss) embryos. Environ Toxicol Chem 20(3):553-560. https://doi.org/10.1002/ etc. 5620200314

Guan Q et al (2012) Cellular memory of acquired stress resistance in Saccharomyces cerevisiae. Genetics 192(2):495-505. https://doi. org/10.1534/genetics.112.143016 
Handy RD (1994) Intermittent exposure to aquatic pollutants: assessment, toxicity and sublethal responses in fish and invertebrates. Comp Biochem Physiol Part C Pharmacol 107(2):171-184. https ://doi.org/10.1016/1367-8280(94)90039-6

Hanson SR, Donley SA, Linder MC (2001) Transport of silver in virgin and lactating rats and relation to copper. J Trace Elements Med Biol 15(4):243-253. https://doi.org/10.1016/S0946 $-672 \mathrm{X}(01) 80040-7$

Hogstrand C, Wood CM (1998) Toward a better understanding of the bioavailability, physiology, and toxicity of silver in fish: implications for water quality criteria. Environ Toxicol Chem 17(4):547561. https://doi.org/10.1002/etc.5620170405

Jezierska B, Ługowska K, Witeska M (2009) The effects of heavy metals on embryonic development of fish (a review). Fish Physiol Biochem 35:625-640. https://doi.org/10.1007/s10695-008-9284-4

Jiang L et al (2013) Sperm, but not oocyte, DNA methylome is inherited by zebrafish early embryos. Cell 153(4):773-784. https://doi. org/10.1016/j.cell.2013.04.041

Juncos R et al (2017) Variations in anthropogenic silver in a large Patagonian lake correlate with global shifts in photographic processing technology. Environ Pollut 223:685-694. https://doi. org/10.1016/j.envpol.2017.02.003

Kägi JHR, Schäffer A (1988) Biochemistry of metallothionein. Biochemistry 27(23):8509-8515. https://doi.org/10.1021/bi00423a00

Kamstra JH et al (2015a) Dynamics of DNA hydroxymethylation in zebrafish. Zebrafish 12:230-237. https://doi.org/10.1089/ zeb.2014.1033

Kamstra JH et al (2015b) Zebrafish as a model to study the role of DNA methylation in environmental toxicology. Environ Sci Pollut Res 22(21):16262-16276. https://doi.org/10.1007/s11356-014-3466-7

Kamstra JH et al (2017) Differential DNA methylation at conserved non-genic elements and evidence for transgenerational inheritance following developmental exposure to mono(2-ethylhexyl) phthalate and 5-azacytidine in zebrafish. Epigenet Chromatin 10(1):20. https://doi.org/10.1186/s13072-017-0126-4

Kang JS et al (2016) Differentially transcriptional regulation on cell cycle pathway by silver nanoparticles from ionic silver in larval zebrafish (Danio rerio). Biochem Biophys Res Commun 479(4):753-758. https://doi.org/10.1016/j.bbrc.2016.09.139

Kille P et al (2013) DNA sequence variation and methylation in an arsenic tolerant earthworm population. Soil Biol Biochem 57:524-532. https://doi.org/10.1016/j.soilbio.2012.10.014

Kim K-T, Tanguay RL (2014) The role of chorion on toxicity of silver nanoparticles in the embryonic zebrafish assay. Environ Health Toxicol 29:e2014021. https://doi.org/10.5620/eht.e2014021

Kimmel CB et al (1995) Stages of embryonic development of the zebrafish. Dev Dyn 203(3):253-310. https://doi.org/10.1002/ aja.1002030302

Kleiven M et al (2018) Route of exposure has a major impact on uptake of silver nanoparticles in Atlantic salmon (Salmo salar). Environ Toxicol Chem 37(11):2895-2903. https://doi.org/10.1002/ etc. 4251

Kumar SSD et al (2018) Recent advances on silver nanoparticle and biopolymer-based biomaterials for wound healing applications. Int J Biol Macromol 115:165-175. https://doi.org/10.1016/j.ijbio mac.2018.04.003

Kwak JI et al (2016) Multispecies toxicity test for silver nanoparticles to derive hazardous concentration based on species sensitivity distribution for the protection of aquatic ecosystems. Nanotoxicology 10(5):521-530. https://doi.org/10.3109/17435390.2015.1090028

Laing LV et al (2016) Bisphenol A causes reproductive toxicity, decreases dnmt1 transcription, and reduces global DNA methylation in breeding zebrafish (Danio rerio). Epigenetics 11(7):526538. https://doi.org/10.1080/15592294.2016.1182272
Lange A et al (2009) Sexual reprogramming and estrogenic sensitization in wild fish exposed to ethinylestradiol. Environ Sci Technol 43(4):1219-1225. https://doi.org/10.1021/es802661p

Lansdown ABG (2006) Silver in health care: antimicrobial effects and safety in use interactions between skin and biofunctional metals. Curr Probl Dermatol 33:17-34. https://doi.org/10.1159/00009 3928

Martin CC et al (1999) A role for DNA methylation in gastrulation and somite patterning. Dev Biol 206(2):189-205. https://doi. org/10.1006/dbio.1998.9105

McGillicuddy E et al (2017) Silver nanoparticles in the environment: sources, detection and ecotoxicology. Sci Total Environ 575:231246. https://doi.org/10.1016/j.scitotenv.2016.10.041

Mirbahai L, Chipman JK (2014) Epigenetic memory of environmental organisms: a reflection of lifetime stressor exposures. Mutat Res Genetic Toxicol Environ Mutagen 764-765:10-17. https://doi. org/10.1016/j.mrgentox.2013.10.003

Ngoc Dung TT et al (2019) Preparation of silver nanoparticle-containing ceramic filter by in-situ reduction and application for water disinfection. J Environ Chem Eng 7(3):103176. https://doi. org/10.1016/j.jece.2019.103176

O'Boyle S et al (2007) Identification of zygotic genes expressed at the midblastula transition in zebrafish. Biochem Biophys Res Commun 358(2):462-468. https://doi.org/10.1016/j.bbrc.2007.04.116

Osborne OJ et al (2016) Sensory systems and ionocytes are targets for silver nanoparticle effects in fish. Nanotoxicology 10(9):12761286. https://doi.org/10.1080/17435390.2016.1206147

Pálfy M, Joseph SR, Vastenhouw NL (2017) The timing of zygotic genome activation. Curr Opin Genetics Dev 43:53-60. https:// doi.org/10.1016/j.gde.2016.12.001

Paquin R, Di Toro DM (2008) Silver biotic ligand model (BLM): refinement of an Acute BLM for Silver. IWA Publishing. doi: $10.2166 / 9781780403656$

Parsons A et al (2019) Molecular mechanisms and tissue targets of brominated flame retardants, BDE-47 and TBBPA, in embryolarval life stages of zebrafish (Danio rerio). Aquat Toxicol 209:99-112. https://doi.org/10.1016/j.aquatox.2019.01.022

Paull GC et al (2008) Variability in measures of reproductive success in laboratory-kept colonies of zebrafish and implications for studies addressing population-level effects of environmental chemicals. Aquat Toxicol 87(2):115-126. https://doi. org/10.1016/j.aquatox.2008.01.008

Peterson RH, Martin-Robichaud DJ (1982) Water uptake by Atlantic salmon ova as affected by low $\mathrm{pH}$. Trans Am Fish Soc 111(6):772-774. https://doi.org/10.1577/15488659(1982)111\%3c772:wubaso\%3e2.0.co;2

Plautz SC, Salice CJ (2013) Plasticity in offspring contaminant tolerance traits: developmental cadmium exposure trumps parental effects. Ecotoxicology 22(5):847-853. https://doi.org/10.1007/ s10646-013-1076-7

Potok ME et al (2013) Reprogramming the maternal zebrafish genome after fertilization to match the paternal methylation pattern. Cell 153(4):759-772. https://doi.org/10.1016/j. cell.2013.04.030

Purcell TW, Peters JJ (1998) Sources of silver in the environment. Environ Toxicol Chem. https://doi.org/10.1897/15515028(1998)017\%3c0539:SOSITE\%3e2.3.CO;2

Razack SA, Duraiarasan S, Mani V (2016) Biosynthesis of silver nanoparticle and its application in cell wall disruption to release carbohydrate and lipid from $C$. vulgaris for biofuel production. Biotechnol Rep 11:70-76. https://doi.org/10.1016/j.btre.2016.07.001

Reinardy HC et al (2019) Effects of mine tailings exposure on early life stages of atlantic cod. Environ Toxicol Chem 38(7):1446-1454. https://doi.org/10.1002/etc.4415 
Schulz KN, Harrison MM (2019) Mechanisms regulating zygotic genome activation. Nat Rev Genet 20:221-234. https://doi. org/10.1038/s41576-018-0087-x

Skvortsova K, Iovino N, Bogdanović O (2018) Functions and mechanisms of epigenetic inheritance in animals. Nat Rev Mol Cell Biol 19(12):774-790. https://doi.org/10.1038/s41580-018-0074-2

Tai ZP et al (2019) Common responses of fish embryos to metals: an integrated analysis of transcriptomes and methylomes in zebrafish embryos under the stress of copper ions or silver nanoparticles, Metallomics. R Soc Chem 11(9):1452-1464. https://doi. org/10.1039/c9mt00125e

Taylor SM, Jones PA (1982) Mechanism of action of eukaryotic DNA methyltransferase. Use of 5-azacytosine-containing DNA. J Mol Biol 162(3):679-692. https://doi.org/10.1016/00222836(82)90395-3

Thamilselvi V, Radha KV (2017) A review on the diverse application of silver nanoparticle. IOSR J Pharm (IOSRPHR) 7(1):21-27. https://doi.org/10.9790/3013-0701012127

Valerio-García RC et al (2017) Exposure to silver nanoparticles produces oxidative stress and affects macromolecular and metabolic biomarkers in the goodeid fish Chapalichthys pardalis. Sci Total Environ 583:308-318. https://doi.org/10.1016/j.scito tenv.2017.01.070

van Aerle R et al (2013) Molecular mechanisms of toxicity of silver nanoparticles in zebrafish embryos, environmental science and technology. Am Chem Soc 47(14):8005-8014. https://doi. org/10.1021/es401758d

van Leeuwen CJ et al (1985) Differences in susceptibility of early life stages of rainbow trout (Salmo gairdneri) to environmental pollutants. Aquat Toxicol 7(1-2):59-78. https://doi.org/10.1016/0166445X(85)90036-0

Vandegehuchte MB, Janssen CR (2011) Epigenetics and its implications for ecotoxicology. Ecotoxicology 20(3):607-624. https://doi. org/10.1007/s10646-011-0634-0
Wang X, Bhandari RK (2019) DNA methylation dynamics during epigenetic reprogramming of medaka embryo. Epigenetics 14(6):611-622. https://doi.org/10.1080/15592294.2019.1605816

Wells PR, Pinder AW (1996) The respiratory development of Atlantic salmon: II partitioning of oxygen uptake among gills, yolk sac and body surfaces. J Exp Biol 199:2737-2744

$\mathrm{Xu} \mathrm{QH}$ et al (2018) Silver nanoparticles impair zebrafish skeletal and cardiac myofibrillogenesis and sarcomere formation. Aquat Toxicol 200:102-113. https://doi.org/10.1016/j.aquatox.2018.04.018

Yang Q et al (2019) Impact of DNA methyltransferase inhibitor 5 -azacytidine on cardiac development of zebrafish in vivo and cardiomyocyte proliferation, apoptosis, and the homeostasis of gene expression in vitro. J Cell Biochem. https://doi.org/10.1002/ jcb. 29010

Ye S et al (2014) Role of DNA methylation in the adaptive responses induced in a human B lymphoblast cell line by long-term low-dose exposures to $\gamma$-rays and cadmium. Mutat Res Genetic Toxicol Environ Mutagen 773:34-38. https://doi.org/10.1016/j.mrgen tox.2014.08.004

Yeo MK, Kang M (2008) Effects of nanometer sized silver materials on biological toxicity during zebrafish embryogenesis. Bull Korean Chem Soc 29(6):1179-1184. https://doi.org/10.5012/ bkcs.2008.29.6.1179

Publisher's Note Springer Nature remains neutral with regard to jurisdictional claims in published maps and institutional affiliations. 